Calev, A. (1988) Effect of emotion on the rate of forgetting in normals, schizophrenics and depressives. Paper presented at the First International Conference on Individual Differences, Tel Aviv, Israel.

Dunbar, G. C. \& Lishman, W. A. (1984) Depression, recognition memory and hedonic tone: a signal detection analysis. British Journal of Psychiatry. 144, 376-382.

Hole, C. \& Castle, R. (1966) Content Analysis of Dreams. New York: Appleton-Century-Crofts

Teasdale, J. D. \& Dent, J. (1987) Cognitive vulnerability to depression: an investigation of two hypotheses. British Journal of Psychiatry, 26, 113-126.

\section{Expressed emotion and lithium prophylaxis}

SIR: In a previous study (Priebe; Journal, March $1989,154,396-399$ ), expressed emotion (EE) in key relatives of 21 patients with bipolar affective or schizoaffective psychoses was assessed by the Camberwell Family Interview (CFI). All patients had been on prophylactic lithium for at least three years. Patients living with high-EE relatives showed a significantly poorer response during the three years before interview and particularly during the ninemonth follow-up.

Twenty-eight months after the initial CFI, the key relatives of 15 patients were re-interviewed. All 15 patients had continued on prophylactic lithium throughout the 28 months. Two critical remarks designated high EE. There were 10 relatives identified with high EE in the first interview and eight in the second, since two relatives changed from high- to low-EE status. The course of patients' illness was assessed by means of a morbidity index (Coppen $e t$ $a l, 1973)$ reflecting severity and length of recurrences (a recurrence was defined by hospital admission or a temporary additional antidepressive or neuroleptic medication).

Regardless of whether EE status was defined according to first or second CFI, morbidity indices concerning the 28-month period were more than six times higher in patients living with high-EE relatives (regarding the first CFI: $t=2.91, P<0.05$; regarding the second CFI: $t=3.83, P<0.01$ ). Four out of five patients with consistently low-EE relatives, and one patient with a relative who had changed from highto low-EE status were virtually without any recurrences during the $2 \dot{8}$-month period. This applied to none of the patients living with consistently high-EE relatives.

A clear answer as to whether high-EE status of relatives leads to an unfavourable course of illness or vice versa was not found. Both course of illness and relatives' $E E$ status might be influenced by interactional patterns in the patients' families, and by changes in those patterns. As far as this small and highly selective sample is concerned, it may be con- cluded that patients living with consistently lowEE relatives rarely need therapeutic interventions of whatever kind in addition to prophylactic lithium.

Department of Social Psychiatry

S. Priebe

Freie Universität Berlin

Platanenallee 19

D 1000 Berlin 19

Department of Clinical Psychiatry

C. WILDGRUBE Freie Universität Berlin

\section{Reference}

Coppen, H., Peet, M., Bailey, J. et al (1973) Double-blind and open prospective studies of lithium prophylaxis in affective disorders. Psychiatry, Neurology and Neurosurgery, 76, 501-510.

\section{Pseudocyesis followed by depressive psychosis}

SIR: Pseudocyesis is a false belief in pregnancy associated with its symptoms and signs (Cohen, 1982). It may be associated with psychiatric disorder, most commonly depression, which usually does not reach case level (Brown \& Barglow, 1971). Occasionally, it is associated with psychosis (Taylor \& Kreeger, 1987; Mortimer \& Banberry, 1988; Milner \& Hayes, 1990). We would like to report the first case of depressive psychosis following pseudocyesis after an interlude of normality.

Case report: A 38-year-old married domestic worker of stable pre-morbid personality had children of ages 20,14 and 10 years. She had had one miscarriage at age 35 years and one elective abortion when 37 years old. Six months after this abortion she was referred to the psychiatric services because she believed herself to be pregnant, despite two negative pregnancy tests. She had missed two periods, had back-ache,breast swelling and tenderness and morning nausea. Examination revealed a distended abdomen but non-pregnant cervix and uterus. After three weeks of supportive psychotherapy all symptoms resolved. She remained completely well for three weeks but then became depressed, with early morning wakening, reduced energy, poor appetite and weight loss. She was severely agitated, believing herself to be in danger. She was deluded that her face was being distorted and that her body was rotting. She made three suicide attempts. Her symptoms failed to respond to antidepressants and phenothiazines but resolved rapidly with a short course of electroconvulsive therapy. She returned to her pre-morbid functioning and has remained well for two years off all medication.

Our patient's illness satisfied DSM-III-R criteria for a major depressive episode with psychotic features and ICD-9 guidelines for manic-depressive psychosis, depressed type. To our knowledge, this is the first report of a depressive psychosis following 